instance, the addition of parts would be a distinct benefit and extend the reach of the collection beyond the classroom and into the rehearsal space, yet would offer only limited value to students enrolled in undergraduate music survey courses. The inclusion of recordings is not within the immediate scope of this project-though it is hinted at in the Heuchemer review noted above $^{16}$ - but could allow libraries to present a complete package to music students in their introductory courses as a substitute for the packaged anthologies and recordings that many students currently purchase. Failing that, it would be useful if the Anthology supported the openURL standard for seamless linking of its content with existing streaming audio databases. In the meantime, this product would work nicely in conjunction with a library's local streaming reserves platform, paired via a course management system.

In addition to the desirable index points mentioned above-for series titles and editors-it would also be helpful if the database included and indexed identifying numbers from thematic catalogs. Finally, one obvious drawback of the Anthology is the dependence on Adobe Flash Player for score rendering. This dependence will typically not inhibit use on a traditional computer, but it does prohibit access from mobile Apple devices. As with e-book products that require a dedicated platform, this shortcoming limits some of what would seem like the natural use of such a product on an iPad.

As is, A-R Editions' Online Music Anthology presents a helpful supplement to print collections and creates a model that targets literature with the broadest need, that of the undergraduate music survey course. Our students are met with increasing textbook costs combined with reduced time and willingness to visit the library. While it is not uncommon for students to try to depend solely on online scores they find in the Public Domain or have acquired through other nefarious means, they would no doubt be better served by an approach that is not so limiting in both availability of contents and in consistency of editorial policy. The Online Music Anthology addresses both of those challenges by creating one central repository to serve the score needs of those students with ubiquitous access from anywhere with an Internet connection, while giving teaching faculty the flexibility to choose from a variety of well-edited source texts, rather than settling on the one or two exemplars of a style from a packaged anthology.

Susannah Cleveland
Bowling Green State University

Chopin Early Editions [Chicago, IL]: University of Chicago, 2004-. http://chopin.lib.uchicago.edu/ (Accessed December 2011). [Requires a Web browser and an Internet connection. Pricing: free.]

Chopin's First Editions Online [London, UK]: University of London, 2004-. http://www.cfeo.org.uk/dyn/index.html (Accessed December 2011). [Requires a Web browser and an Internet connection. Pricing: free.]

By engaging different publishers in France, Germany, and England, Fryderyk Chopin ably navigated early nineteenthcentury European copyright laws, and this savvy combined with variations of source materials and Chopin's apparent lack of control over the publishing process outside of Paris effectively resulted in three 'first editions' of most of his compositions. The textual discrepancies between the three editions naturally problematized ensuing published collections, making posthumous attempts at collected and/or critical editions profoundly inconsistent. Beginning in 2004, two different online projects were created to address this quagmire of editing

16. Heuchemer, p. 68. 
woes: Chopin Early Editions and Chopin's First Editions Online.

\section{Content and Scope}

Chopin Early Editions is a digitized version of the Chopin collection at the University of Chicago Library, which comprises over 400 first and early printed editions, preserved in the Special Collections Research Center. The collection's scope includes individual works, as well as collected editions published before 1881 (identified as a cutoff date due to the 1878-80 Works, published by Breitkopf \& Härtel). Information regarding the collection's production timeline is not provided on the site, but a copyright year of 2004 on the main page suggests that no extensive amount of content or design has since been added or changed.

Originally funded by the Arts and Humanities Research Council (Resource Enhancement Programme) between 2004 and 2007, the aim of Chopin's First Editions Online is to unify all of the first impressions of Chopin's first editions from five main institutions (Bibliothèque Nationale de France, Bodleian Library, British Library, Narodowy Instytut Fryderyka Chopina, and the University of Chicago Library) and seventeen other libraries. As of 14 September 2011, the collection boasted around 5,500 digital images. In addition to digital representations of the physical items, textanalytical commentary and online catalogue excerpts are included to highlight the major differences between various first editions, contrasting their chronological and filial relationships.

\section{Interface Design}

The interface for Chopin Early Editions is a clean, spacious design that favors lighter colors and hence reduces visual noise, encouraging the user's eye to focus on the content. Simple buttons for main navigation offer a search button and browsing options of titles, uniform titles, genres, and dedicatees. Lists for the latter three categories fit on one Web page each, whereas titles are subdivided alphabetically underneath the main navigation. Each subdivision contains listings that include publication information and uniform titles, sometimes indented inconsistently, due to varying lengths of text. When any given title is clicked, the default view shows a bibliographic description tab that contains standard, un-hyperlinked cataloging fields.

Images are accessed by clicking the "view score" tab, which provides the user a view of the scanned pages that in general is easy to visually skim. Users also have the option to view a higher-quality image by clicking a hyperlink at the bottom of the page. The high-resolution images are zoomable JPEGs (enabling the user to save them to the computer or some other form of storage), and all images include rulers on the side. An expandable menu in the upper right-hand corner of the viewing window enables quick navigation of the item's pages, whereas "previous" and "next" buttons for page-bypage browsing are somewhat curiously located underneath the images.

Probably due to its later genesis, Chopin's First Editions Online appears to have a more updated interface within the larger site's design template. A tab on the main navigation called "View Chopin's First Editions" defaults to a collapsed browsing list for the works, organized first by opus number and then alphabetically by title for those without opus numbers. Expanding each piece's entry within the browsing list results in links for publication history and the extant first editions of each country in which they were published (French first edition, French second edition, Austrian first edition, etc.). The publication histories include a general introduction to the work, a listing of manuscripts relevant to the published editions, and analyses of printed sources as well as the publication process. In addition, each country's edition has a source information page, listing information for publishers, place of publication, dedicatees, series information, plate numbers, publication date, printing method, contents, locations of displayed copy and similar copies, and information on subsequent reprints.

The individual images are presented using Zoomify, which allows the platform to pull images from the various institutional servers. Basic navigation functions within the viewing window include zooming in and out, directional navigation using arrows, a grab tool that allows manipulation of the image's location with the mouse, and a reset button that returns the image to its default display settings. "Previous" and 
"next" buttons enable page turning, or the user can manually click the page link on the left-hand navigation (which lists both page and measure number). Page load time-whether it be in the left-hand navigation of pieces and their various editions or the actual images in the viewing windowappears to be noticeably slower than Chopin Early Editions, most likely due to the fact this resource is pulling content from various locations, instead of one server.

\section{Indexing and Searching}

The search function for Chopin Early Editions allows field-specific searches for titles, uniform titles, date, opus number, place of publication, publisher, dedicatee, subject, genre, plate number, and general keyword. Limiting is restricted to some or all of the search terms, which, given the fact several fields are searchable, does not seem problematic. A page titled "Creating the Digital Collection" describes structural aspects of the Web site, including that the site was constructed using the Greenstone Digital Library software, metadata was converted to MODS (Metadata Object Description Schema) and METS (Metadata Encoding and Transmission Standard), and structural metadata were originally recorded in a Microsoft Access database during digitization.

Searching Chopin's First Editions Online simply involves expanding the "Search" tab of the left-hand navigation, which allows the user to search across the fields of genre, key, publisher, dedicatee, city and country of publication, location of sources, plate number, and a range of years. The aforementioned browsing list remains displayed while the list repopulates in response to the search terms, creating a feel of fluidity to the user's navigation experience. Dedicatees and plate numbers are the only fields with open search boxes, so limits are built in to the overall search function. The Web site provides a fair amount of historical background for the physical editions themselves, a user guide (for further scholarly information about publication histories, source descriptions, sigla, ab- breviations, glossary, and a bibliography) and links; however, there does not appear to be published information regarding the technical aspects of the database design or metadata standards. A section dedicated to the project describes its significance, general project methodology, participants and digitization standards, as well as affiliated projects, the most important of which appears to be Christophe Grabowski and John Rink's Annotated Catalogue of Chopin's First Editions, a source that is mentioned in each of the digital items' source information page.

\section{Summary}

In conclusion, Chopin Early Editions and Chopin's First Editions Online are two different resources that appeared in close succession, with different scopes and goals. Chopin Early Editions is a digital collection of items held specifically at the University of Chicago and includes editions published before 1881, regardless of whether they were "first editions." As such, it is an interesting and impressive early effort by one institution to recognize the importance of digitizing these items for scholarly comparison, making the most of what tools were available at the time and achieving a high level of success, from this user's perspective. Chopin's First Editions Online, on the other hand, represents the efforts of a team of people across institutions, realizing the collective potential of pooling institutional resources (in this case, digitizing items at different locations) to create a more synthesized perspective on only first editions, thereby empowering the user to compare and contrast across a wider geographical area, from both a publisher- and libraryspecific perspective. Its later genesis allowed Chopin's First Editions Online to enjoy more benefits from technological developments, however the differences in scope between these two resources keeps their own value to scholars and performers of Chopin's works alike.

Andrew Justice University of North Texas

Opera in Video [Alexandria, VA]: Alexander Street Press, 2008-. http://opiv.alexanderstreet.com/ (Accessed October 2011). [Requires a Web browser (Windows 98 or higher, Apple version OSX/OSIO or 